\title{
LIX. The formation of meteorites, and volcanic agency
}

\section{Prof. G. Tschermak}

To cite this article: Prof. G. Tschermak (1876) LIX. The formation of meteorites, and volcanic agency, Philosophical Magazine Series 5, 1:7, 497-507, DOI: 10.1080/14786447608639074

To link to this article: http://dx.doi.org/10.1080/14786447608639074

曲 Published online: 13 May 2009.

Submit your article to this journal $\pi$

Џll Article views: 3

Q View related articles $\sqsubset$ 
LONDON, EDINBURGH, AND DURLIN

\title{
PHILOSO PHICA L II A G AZINE
}

\author{
AND \\ JOURNAL OF SCIENCE.
}

SUPPLEMENT to VOL. I. FLFTH SERIES.

LIX. The Formation of Meteorites, and Volcanic Ayency. $B y$ Prof. G. Tschermak, Director of the Imperial Mineralogical Museum of Vienna *

THEE researches of Howard, Klaproth, Vauquelin, and 1 Berzelius on the elementary composition of many specimens of meteorites proved that the matter of which they are constituted is, generally speaking, such as occurs in greater abundance in the crust of our globe. Before then Chladni had established the planetary nature of these remarkable masses.

From these results taken together it may be assumed that the other heavenly bodies are built up of the same materials as those composing our globe. But this assumption has become a certainty, as regards the central body of our system, from the spectroscopic investigation of the light of the sun, initiated by Kirchhoff and Bunsen, while the observations of Secchi, Huggins, and Miller on the spectra of the fixed stars render it highly probable that the universe is formed of similar elementary materials.

Our conception of the material nature of the heavenly bodies is founded on the analysis of meteorites; and accordingly a study of the form of meteorites is likely to afford some insight as regards the antecedents of the star-masses whence they are derived, and the changes which they have undergone.

The external form of meteorites is remarkable in many respects. Hitherto but little attention has been directed to the very curious fact that meteorites reach us in the shape of fragments. It is well known that any one who has merely

* Translated from the Sitzungsber. der k. Akademie der Wissenschaften, vol. Ixxi. p. 661, by Dr. WValter Flight, of the Mineral Department, British Museum.

Plil. Mag. S. 5. No. 7. Suppl. Vol. 1.

$2 \mathrm{~L}$ 
read of the planetary nature of meteorites, experiences no little astonishment, on inspecting a collection of them, to find that they are not rounded as the planets are, but are angular, often exhibit sharp edges, and possess, even in their interior, no concentric structure.

Haidinger, who examined with much care the surfaces of meteorites, arrived at the conviction that their dark-coloured crust and the rounded nature of their edges were not original characteristics, but that the thin crust was developed during transit through the atmosphere, the sharpness of the edges being at the same time abraded. A meteorite, in short, before entering the atmosphere possesses an angular form; the greater number are acutely angular. The faces of the angular masses are surfaces of fracture; each meteorite is a fragment, and in fact owes its form to the disruption of a larger mass.

Any collection, in which complete meteorites are preserved, will furnish examples which conclusively demonstrate this fact; and among the specimens at Vienna attention may especially be directed to the meteoric iron of Agram, that of Ilimaë, and the stones of Knyahinya, Seres, Lancé, Chantonnay, Orvinio, Tabor, Pultusk, Stannern, and others. The external form of these and other meteorites bears no relation whatever to the constitution of their interior; it is purely accidental.

It may perhaps bo maintained that the disruption took place in the atmosphere; and there are unquestionably a few instances where an inspection of the crust shows that the meteorite had been sundered during its flight through the atmosphere; the fact, however, remains that meteorites enter our atmosphere in the form of fragments. After the aerolitic fall which took place near Butsura, India (May 12th, 1861), five fragments were discovered, some of them as much as six miles apart; by fitting these pieces together Maskelyne was able to reconstruct in London the meteorite in the form which it originally bore, and which appears to have been that of a comparatively thin slab somewhat bent. The irregular heating to which such a body would be subjected during its fall would lead to its disruption. With this example, it is scarcely necessary to direct attention to other cases which establish the fact that meteorites when they enter our atmosphere do not have the rounded form of planetary bodies.

Meteorites, then, always reach us in the shape of fragments, as flattened masses, or as fine particles, which have their origin in one or more larger planetary masses. Whether the source be one or many, the dimension of this mass or these masses must have been not inconsiderable. 
The greater number of meteoric irons exhibit a structure which indicates that each has formed part of a large mass possessing similar crystalline characters. The formation of large masses so constituted, presupposes, as Haidinger has pointed out, long intervals of time for tranquil crystallization at a uniform temperature; and these conditions could only prevail on one of the larger cosmical masses. On the surfaces of many meteorites (such as the Château-Renard, Pultusk, and Alessandria ones) indications resembling in every particular the "slide" or "throw" of terrestrial rocks are to be met with, appearances which indicate the disruption or dislocation of larger masses. Other meteorites, like those of Tula, Chantonnay, Orvinio and Weston, are congeries of angular fragments, and correspond, as regards structure, with terrestrial breccias. Many stones, moreover, are formed of very small fragments, of tiny splinters, and resemble volcanic tuffs. These characters, again, point to larger cosmical masses which have undergone mechanical changes as the source whence they have been derived.

So far, then, it would appear that the material of which meteorites consist has been furnished by one or more large masses, the formation of which must have occupied a long period of time. The question which therefore suggests itself is, How is the process of disintegration to be accounted for? This Daubrée endeavoured to solve, and arrived at the alternative that disintegration must be the effect either of impact or explosion*.

The idea that the smaller planetary bodies were formed by the impact and disruption of larger cosmical masses was propounded by Olbers $\dagger$ to account for the existence of the asteroids; and D'Arrest and C. von Littrow have in more recent times established, by careful calculation, the possibility of the impact of these bodies actually taking place.

By the impact of two solid cosmical masses, moving with planetary velocity, fusion, perhaps even vaporization, would occur over the area of contact $f$; disintegration, moreover,

* G. A. Daubrée, Journal des Savants, 1870.-Meunier (Géologie Comparee, 296) seeks to escape from this dilemma by supposing a spontaneous disruption of the planetary mass to have taken place in much the same way as a disk of clay crumbles on drying. Even if we allow this explanation to be a possible one, the further difficulty presents itself, that the fragments would continue to traverse one and the same orbit, which, with the meteorites, we know is not the case.

+ Zach, Monatl. Correspondenz, rol. vi. p. 88.

$\mp$ A cosmical mass possessing a velocity of three geographical miles, and by impact with another mass being brought to a state of rest, would, on the supposition that all the vis viva was converted into heat and none $2 \mathrm{~L} 2$ 
would be a result; the fragments would be sundered with great violence, and would acquire velocities in several directions. The formation of meteorites may thus be explained; we must, however, not lose sight of the fact that during such a disruption large fragments, as well as small, would be produced. Meteorites, however, are always small masses. The largest known are the meteoric stone of Knyahinya, in the Vienna Collection, which weighs 294 kilog., and the meteoric iron of Cranbourne, preserved in the British Museum, and weighing 3700 kilog. Most of them are of far less magnitude ; and a stone of 5 kilog. is accounted a large meteorite.

All these masses, even the largest, are but tiny splinters or fine dust in comparison with a very small planet of only a mile diameter. Were the latter divided into a million equal parts, one of them would be 250,000 times the size of the Knyahinya stone, and 10,000 times as large as the Cranbourne meteoric iron.

It appears, therefore, to be highly improbable that meteorites owe their form to the disruption, by impact, of planetary masses ; it is much more probable that a disintegration, even to the smallest particles (what may be termed a pulverization), has been brought about by a force acting from within outwards-in short, by an explosion.

Explosion is a violent process, and may appear to clash with our ideas of gradual cosmical development; yet it is not more violent than the movements observed on the surface of the sun, or those of the comets, whether observed or calculated. The explosive upheavals on the sun observed by Zöllner, Young, and Respighi, the cyclonic movements, as determined by Lockyer, proceed at far greater velocities than have ever been observed in the case of terrestrial explosions.

Again, the sudden blazing-forth of certain stars is evidence of the activity of some vast force, which Mayer traced to the impact of fixed stars and their union after fusion. The emanations observed in comets by Schmidt take place with a vigour which also implies very rapid movement. There is nothing in any of these phenomena at all at variance with the assumption of an explosion or pulverization of a cosmical body. Whether the cosmical mass or masses which have furnished the meteorites are to be ranked with the fixed stars,

of the heat dissipated, develop for each unit of weight 59630 units of heat. If we assume one half the heat to be lost by radiation and conduction, and the specific heat of a meteoric stone to be five times as great as it is (that is to say, as =1), in order to compensate for the increase of specific heat with the temperature and for the heat of fusion, the rise of temperature would still be $=29800^{\circ} \mathrm{C}$. 
the planets, or the comets, the inference which we need not hesitate to draw in either case is, that the masses in question have been disintegrated by explosion.

Here, however, we have to meet the same objection as in the theory of disintegration by impact. When a cosmical body of considerable magnitude, whether solid or in part fluid, is sundered by explosion, there will be produced, in addition to the numberless small fragments, large masses also, which become meteorites, and set out in various orbits. We must not, however, lose sight of the fact that meteorites, as we know them, are, comparatively speaking, very small bodies ; and for this reason we cannot support the view that the complete breaking asunder of the mass had occurred at a single explosion. But the disintegration of such a cosmical mass may be gradual. In place of a single explosion, we can conceive a succession of them hurling portions of the surface into space. Such an occurrence may take place on any cosmical mass on which volcanic agencies may be active, and the mass yet be so small that its gravitating power is insufficient to attract again to its surface all the fragments which have been hurled from it.

Such considerations recall to mind the views long since propounded by Olbers, Arago, Laplace, Berzelius, and others, and recently put forth by Dr. Lawrence Smith, according to which the moon, the gravitating force of which is one sixth that of the earth, could propel fragments to such distances that they would not return to her. The possibility of such an occurrence in the case of the moon cannot be gainsaid; the lunar surface covered with its numerous cratermounds shows that the greater portion of the ejected masses have descended again to form the stony ramparts surrounding the crater-mouths, and that even under the most favourable conditions only few fragments have been scattered into space. When the amount of meteoric matter which reaches our earth annually is considered, such a source as the one in question appears to be too insignificant. The meteorites reach us from such a variety of directions, and fall so frequently, that we must seek for a more general cause, lying not in the moon alone, nor, in short, in any single member of the system of heavenly bodies.

In a number of cosmical bodies, then, of considerable dimension, yet sufficiently small to be unable to attract again to their surface fragments hurled from them by explosion, it is possible to conceive the conditions under which meteorites are fashioned. It is highly probable that small starmasses of such a kind may, during a certain period of their 
existence, exhibit violent explosive activity, if we may judge by analogy from the moon, which has passed through a stage of much more intense volcanic activity than we have any experience of. Such smaller star-masses continue to lose in mass by constant projection of fragments, until at last they themselves are resolved into small portions, and traverse the universe in orbits of the most varied kind.

We might feel inclined to recognize in the comets the débris of such small star-masses, and to detect in their emanations the last phase of that activity which we have described. That, however, is beyond our province; and it must be left to those investigators who deal with the question of the nature of comets to decide whether the observations already made are calculated to establish such a connexion*.

It will suffice here to have shown that the form of meteorites may be assumed to be due to violent movements of the original star-mass acting from the interior towards the surface. Similar movements are at present taking place on the earth and on the sun, while at an earlier period it was by such movements that the craters of the lunar surface were built up. On different star-masses the cause of these movements may be different; and so long as the cause is in any instance unknown it is permissible to term all these movements volcanic.

Whether the action be simply explosive, hurling upward the solid rock of the surface, or at the same time also eruptive, as on the earth, ejecting matter from the interior, in either case a difference will be observed between the crust and the nucleus of the rock. As meteorites reach us in the form of angular fragments, it follows that the star-mass whence they are derived must have possessed a solid crust; further, we must conclude that the interior was either not solid, or had an altogether different constitution.

Guided by their form we might trace the origin of meteorites to smaller star-masses, constituted similarly to our earth, which by volcanic activity have been gradually reduced to fragments. The texture of the meteoric rock carries us a step further towards obtaining a glimpse at the history of the star-mass before its disintegration.

It has already been stated that the constitution of many of

* There are many who trace a connexion between the meteorites and the shooting-stars because the atmospheric phenomena in each case are almost entirely the same. As the connexion between the comets and the shooting-stars had been discovered and explained by Schiaparelli, a relation between the comets and the meteorites followed as a matter of course. A difficulty, however, is presented by the fact that the maxima of frequency of star-showers in no way accord with the most abundant aerolitic falls. 
the meteorites shows that they are the result of a gradual tranquil crystallization, while others, on the contrary, are composed of fragments, and are the product of disintegrating forces. The majority are made up of minute flakes and splinters and of rounded granules.

Haidinger was the first who ventured to compare the porous masses, made up of rock-dust, with the triturated and pulverized products of terrestrial volcanoes, and to term them meteoric tuffs. The marked preponderance of this structural character in meteorites shows that in the star-masses whence they were derived a state of quiescence must have been of much rarer occurrence than one of volcanic activity.

In the tufaceous meteorites a characteristic feature presents itself which throws considerable difficulties in the way of our explanation, a phenomenon which is not observed in so marked a degree in the tuffs of our volcanoes. It is the occurrence in great abundance of minute rounded particles and spherules which at once arrest the attention of the observer. They characterize all tufaceous meteoric stones which, as already stated, constitute the largest class of these bodies, and which were termed by Rose " chondritic."

These spherules present the following features, which suffice to enable us to recognize their mode of formation *:-

1. They are imbedded in a matrix consisting of fine or coarse splinter-like particles.

2. They are invariably larger than these particles.

3. They are always distinct individuals, never merging into each other or joined together.

4. They are quite spherular when composed of a tough mineral, and in other cases merely rounded in form.

5 . They consist sometimes of one mineral, sometimes of several minerals, but always of the same material as the matrix:

6. The structure of the interior of a spherule is in no way related to its external form. They are either fragments of a crystal, or have fibrous structure (the fibres taking an oblique direction towards the surface), or have irregularly barred structure, or they are granular.

These chondra bear no indications of having obtained their spherular form by crystallization, and cannot be classed with spherolitic obsidian or perlite, the spherules of orbicular diorite, or the rounded concretions of calcite, aragonite, or marcasite.

* Drawings of these spherules are given in the papers by Tschermak on the Gopalpur meteorite (Sitzungsb. Ak. Wiss. Wien, lxv. 122) and on the Orvinio meteorite (Sitzungsb. Ak. Wiss. Wien, lxx. Abth. i.), and that by Von Drasche on the Lancé stone (Mineralogioche Mitt. 1875, i.). 
They resemble rather the spherules which are frequently met with in our volcanic tuffs, such as the chondra of the trachyte tuff of Gleichenberg, those of the basalt tuff of the Venusberg, near Freudenthal, and more especially the spherules of olivine of Kapfenstein and Feldbach in Styria.

As regards the last-mentioned chondra*, we know them to be the result of volcanic trituration, and to owe their form to a prolonged explosive activity in a volcanic " throat," where the older rocks have been broken up and the tougher particles have been rounded by continued attrition.

The characters of the meteoric chondra indicate throughout a similar mode of formation $t$. We may at any rate conceive the rock-masses which suffered trituration to have possessed a somewhat soft texture, and thus arrive at an approximation to Daubrée's view $\ddagger$ of a rock-mass which assumed a solid form while rotating in a gaseous medium; it is certain, in short, that the spherules are the result of trituration.

The spherules are sometimes microscopically small, have sometimes the size of a millet-seed; others may be as large as a cherry or a small hazel-nut; but they are not numerous. The tufaceous chondra of our volcanic rocks vary in size from that of a hazel-nut to that of a head. If from this disparity we may form any conception of the different magnitudes of the areas of activity in which they have been produced, we must seek in numerous minute volcanic fissures for the source of the meteoric tuffs.

The latter are peculiarly characterized as containing no trace of a slag-like or vitreous rock, nor enclosing distinct crystals in the matrix; in short they exhibit nothing which their formation from lava would lead us to look for. All that is to be seen in them is the triturated product of a crystalline rock.

Some of the tufaceous meteorites bear evidence of a later modification wrought by heat: such are the stones of Tadjera and Belgorod $\$$. Others, again, exhibit phenomena which can only be explained on the theory of their having undergone a chemical change subsequent to their formation. We not unfrequently find, for example, in the meteorites of MezöMadaras and Knyahinya concentric aggregations of metallic

* They must not be confounded with the rolcanic bombs which are composed of lava.

$\dagger$ Reichenbach considered the chondra to be small meteorites. Here, however, the aim is merely to form a conception of a planetary form of meteorites.

I G. A. Daubrée, Journal des Savants, 1870, 38.

Sitzungsb. Akad. Wiss. Wien, vol. lxx. Abth. i. November Heft. ; and S. Meunier, Compt. Rend. vol. lxxii. p. 339. 
iron enclosing the chondra, which in a microscopic section of the stone present much the same appearance as the halo surrounding the lunar disk; similar appearances are likewise to be often observed in the spherule itself. All tufaceous meteorites have, disseminated throughout their mass, innumerable minute spangles of nickel-iron. These phenomena premise the reducing action of a gas; and Daubrée assumes that hese changes have been wrought by hydrogen. The discovery of hydrogen in the Lenartó meteoric iron by Graham, and the fact of the presence of hydrogen in the sun, established by Kirchhoff, support this view. An exposure to high temperatures in such a case is, of course, likewise assumed.

Distinct evidence of such exposure is, moreover, to be met with in the case of meteorites which consist of fragments cemented together with material of similar composition to those fragments, as in the case of the stones of Orvinio and Chantonnay*. Still, with the many proofs which we possess of the action of heat, we have not yet met with a meteorite which resembles a volcanic slag or a lava. Although the meteorites are comparable to volcanic tuffs and breccias, this comparison cannot be extended beyond a certain point. The volcanic activity, of which the meteorites furnish evidence, consisted in the disintegration of solid rock, in the modification, by heat and otherwise, of already solidified masses. Outflows of lava, and ejection of lava-glass and crystals, which, as Zirkel has shown, form volcanic ash, have not taken place in the case in question.

It is, then, by explosive activity, and that alone, that the breccias and tuffs which we find in meteorites have been formed. We are here forcibly reminded of a similar terrestrial phenomenon with which most are familiar, since in the "Maars" of the Eifel we have what must rightly be regarded as craters of explosion, and a proof that our earth also can furnish an instance of voleanic explosive activity without eruption of lava.

The question which still has to be considered is, What is the cause of that volcanic activity which has subjected the rock forming the surface of such a star-mass to disintegration and trituration, and by which the entire mass of a heavenly body may gradually be reduced to fragments?

The question does not limit itself to what we have dwelt on, but embraces a general consideration of cosmical volcanic agency. Both on the sun and on our earth it is by means of gases and vapours that volcanic energy is transmitted. On the moon we find no traces of an atmosphere, which it would

* Silzber, Akad. Wiss. Wien, vol. lxx. Abth. i. November Heft. 
probably have possessed if the lunar craters had been formed by gaseous explosion. In view of this difficulty a suggestion has been put forth in a recently published work*, that the volcanic activity on the lunar surface has been due to expansion attending solidification. Were this a correct interpretation, it would equally follow that during the freezing of water, which also expands on becoming solid, eruptive phenomena, accompanied by the formation of craters, would certainly be occasionally observed; but such, it need hardly be stated, are unknown. It appears to us, however, that the difficulty which would be disposed of by such an hypothesis has never actually been presented. It cannot have been by means of permanent gases alone that the volcanic changes on the moon have been brought about; and if vapours took part in these operations they must have been subsequently absorbed by the rocks forming the lunar surface. We have, however, thus far not been driven to have recourse to Sämann's theory $\dagger$, according to which the surface of the moon was at an earlier epoch covered with water which has subsequently been absorbed. We shall defer the examination of this subject to a later occasion.

All these considerations, then, have led us to the conclusion that volcanic agency, resulting in the disintegration and distribution of rocky masses in space, is inconceivable without the simultaneous action of gases or vapours, or of perhaps both. From this it follows as a direct inference that the explosive activity, to the existence of which meteorites bear evidence, is due to the sudden expansion of gases or vapours, among which hydrogen may have been a prominent agent.

The conclusions arrived at from the careful investigation and comparison of meteorites, confirm the results obtained during the last few years by students of geology and astronomical physics. The volcanic activity of which those mysterious masses of stone and metal are evidence may be compared to the violent movements on the solar surface, the more feeble action of our terrestrial volcanoes, or the stupendous eruptive phenomena of which the lunar craters tell the history.

No one who at this juncture bears in mind Kant's theory of the homogeneous development of stellar masses, can fail to be struck with the idea that the heavenly bodies already alluded to are not the only masses which have undergoue these changes, but will rather incline to the opinion that volcanic activity is a cosmical phenomenon in the sense that

* Nasmyth and Carpenter, 'The Moon'(London, 1874), p. 98.

+ Sämann, Bull. Soc. Géol. [2] xviii. 322. 
all star-masses at a stage of their development exhibit a phase of volcanic activity. And it is possible that during this period many of those masses which are of comparatively trifling magnitude may have been partially or wholly broken up and resolved into small fragments.

LX. On the Nebular Hypothesis.-II. Interaction. By PLINY Earle Chase, Professor of Philosophy in Haverford College.

[Continued from p. 319.]

TTHE tendency of vibrations in elastic media to produce har1 monic vibrations, combined with the tendency to geometrical and harmonic as well as to arithmetical progressions, should prepare us to look for relations of various complexity when we study the mutual actions and reactions of planetary masses.

The triangular numbers, $1,1+2,1+2+3,1+2+3+4$, appear as indices in the following equation among powers of the masses of the five principal bodies in the solar system :-

$$
\left(\frac{\Psi}{\odot}\right)^{x} \times\left(\frac{\odot}{\odot}\right)^{3} \times\left(\frac{4}{\odot}\right)^{6}=\left(\frac{h}{\odot}\right)^{10} \text {. }
$$

This appears to be the first equation ever discovered which introduces the products of powers of masses in so systematic a form *. Although its full interpretation may be at present beyond our reach, we can catch glimpses of its meaning, and we may feel a reasonable assurance that it represents some important functional law of equilibrating tendencies between centripetal and centrifugal forces. The truth of the equation is, of course, independent of any assumption with regard to the proper unit of comparison; but the dominance of the solar influence lends interest to the æsthetic harmony afforded by its introduction. This interest is increased by the accordance between the order of position and the magnitude of the indices in the left-hand member of the equation, and by the fact that the nebular centre of planetary inertia $\left(\sqrt{\Sigma m r^{2}} \div \bar{\Sigma} m r\right)$ is in Saturn's orbit.

There is still some uncertainty as to the masses of Neptune and Uranus; so that it is impossible to tell how close this agreement may be; but the deviation from precise accuracy cannot be large. According to Newcomb's latest determinations of

* Laplace, however (Méc. Cél. II. vol. viii. pp. 65-69; VI. vol. ii. pp. $12-16, \& c$.$) , investigated inequalities depending on squares and products$ of the disturbing forces. In his discussions of the Jovian and Saturnian systems he introduced terms containing the third and fifth dimensions of eccentricities and inclinations. 